\title{
Pulmonary arteriovenous malformations
}

Arterial venous abnormalities within the lung range from very small lesions resembling spider naevi, such as those in the hepatopulmonary syndrome, to large complex abnormalities. These are virtually all congenital, although there is a small group of acquired lesions. It is the congenital pulmonary arteriovenous malformations that are addressed in the paper by Haitjema and colleagues on pages 719-723 of this issue of Thorax. ${ }^{1}$ Pulmonary arteriovenous malformations are uncommon and are often associated with hereditary haemorrhagic telangectasia. In one series ${ }^{2} 88 \%$ of the cases of pulmonary arteriovenous malformation had haemorrhagic telangectasia, but the more generally quoted figure is around $50 \%$.

The most common symptom is breathlessness, although this may only be elicited on direct questioning. Haemoptysis and haemothorax may occur, but a common presenting symptom of an index case is a cerebrovascular event including transient ischaemia attacks, stroke, or brain abscess. Many of the other cases of pulmonary arteriovenous malformation are then found by screening family members as in this current paper. ${ }^{1}$ Screening should include measurement of arterial blood gases, both on air and $100 \%$ oxygen, and chest radiography. Even if the chest radiograph is normal, computed tomographic (CT) scanning of the chest is indicated if the blood gas results indicate a shunt. This is particularly useful if a spiral CT scan can be performed. ${ }^{3}$ Although some would omit the CT scan on the basis that it is superfluous as pulmonary angiography would be needed to plan treatment in any case, a recent paper by Remy et $a l^{4}$ showed that a three-dimensional reconstruction from a spiral CT scan could show the anatomy of a pulmonary arteriovenous malformation with a high level of accuracy, and decisions whether to treat or not could be made on that basis alone.

Which pulmonary arteriovenous malformations should be treated? There is a group who would require treatment for symptoms including breathlessness, chest pain, palpitations, haemoptysis, and even large haemothoraces due to the pulmonary arteriovenous malformations. A large group may be picked up on screening of relatives, and one third of these may be entirely asymptomatic as in this series. A literature review by Burke et $a l^{5}$ showed significant morbidity and mortality due to cerebrovascular accidents and brain abscess if lesions are untreated. This has been correlated with a pulmonary arteriovenous malformation feeding artery of more than $3 \mathrm{~mm}$. At this level it is generally accepted that pulmonary arteriovenous malformations should be treated, although in 1991 RemyJardin et $a l^{6}$ described two patients with pulmonary arteriovenous malformations with "non-dilated feeding arteries" requiring surgical treatment for repeated brain abscesses.

This paper by Haitjema et al reinforces the low morbidity of embolisation. The most common complaint is of self limiting pleurisy which is felt to be due to infarction of lung distal to the coil. Changes may be seen both on chest radiography and follow up CT scanning. Late effusion may also occur. Reviewing the largest series from Haitjema, White, ${ }^{2}$ Remy-Jardin, ${ }^{6}$ and Jackson, ${ }^{7}$ coil or balloon migration into the systemic circulation was potentially the most serious complication, although there were no serious sequelae except those described in this current paper which were felt to be associated with retrieval of the coil.

The critical part of embolisation is being able to obtain a stable catheter position in the feeding vessel of the pulmonary arteriovenous malformation. Embolisation should be as close to the neck of the arteriovenous communication as possible. The enlarged feeding arteries to these arteriovenous malformations often appear to have no side branches supplying the parenchyma while the shunt is present, but this is simply due to a steal phenomenon and almost invariably multiple small side branches which only fill after the occlusion of the shunt would be present. A coil position at the neck of the pulmonary arteriovenous malformation preserves these more proximal branches and prevents unnecessary lung infarction. Embolisation is more straightforward if the pulmonary arteriovenous malformation has a single feeding vessel (simple pulmonary arteriovenous malformation) rather than a complex pulmonary arteriovenous malformation with more than one feeding vessel. In the paper by Haitjema et al only $20 \%$ of pulmonary arteriovenous malformations were simple while $80 \%$ were complex, which is the reversal of previous studies by White $e t a l^{2}$ where approximately $80 \%$ were simple and $20 \%$ complex.

After a stable position has been obtained, the correct choice of coil size is essential. Too small a coil may migrate into the systemic circulation, particularly in simple pulmonary arteriovenous malformations which tend not to have internal septa. This obviates the use of particulate material for embolisation. Too large a coil would elongate on insertion and would not have the desired occlusive effect. Complete occlusion of the feeding vessels at the time of angiography is essential or recanalisation will occur. The availability of coils that can be almost fully deployed before detachment has helped the angiographer. At angiography the pulmonary artery pressure should be measured, as there may occasionally be associated pulmonary hypertension (approximately 1\%) when occlusion of pulmonary arteriovenous malformations may be contraindicated. Pulmonary hypertension may also occur after closure of pulmonary arteriovenous malformations.

A surgical review by Puskas et $a l^{8}$ which documented 21 patients collected over 28 years emphasises the relative rarity of these lesions. In the early years eight of these had no treatment, four were lost to follow up, and one was only recognised just before death due to heart failure. The three who were followed long term all had strokes, two at a relatively young age and one also had a brain abscess at another time. Nine patients had surgical resection without mortality or significant morbidity, and in one of these patients the surgery was performed after recanalisation following previous balloon embolotherapy. There was no documented recurrence of pulmonary arteriovenous malformation in any of these patients in a median follow up period of 12 years. In this paper the surgical results were compared with five patients undergoing balloon embolotherapy who had distinctly poor results. This comparison led to the unequivocal statement that surgery should be the treatment of choice. Such a conclusion would not be valid when compared with the morbidity and mortality 
figures of the larger embolotherapy series previously mentioned.

In cases of pulmonary arteriovenous malformation with feeding vessels more than $3 \mathrm{~mm}$ a decision between surgery and embolotherapy is required. Unquestionably there is a small group in whom embolisation is technically not possible and in whom surgery must be the choice. Similarly, in patients with multiple pulmonary arteriovenous malformation in several lobes surgery would be potentially too extensive and embolotherapy would be the undoubted treatment of choice. Morbidity appears to be comparable for surgery and embolotherapy, but embolotherapy should preserve the maximum amount of lung possible. Although there will be a small rate of recanalisation of pulmonary arteriovenous malformations that have been embolised, new lesions in patients who have had surgery are also documented, as one would expect in a disease such as this. Neither surgery nor embolisation will eradicate the shunt as there will be persistent small pulmonary arteriovenous malformations and antibiotic coverage for dental treatment is still recommended. The results from this paper by Haitjema et al reinforces the message of other papers on embolotherapy and, with improvements in techniques including detachable coils, embolisation appears to be the primary choice for treatment if technically possible.

Killingbeck Cardiothoracic Hospital and St. Fames's University Hospital,

R J H ROBERTSON Leeds, UK

St. Fames's University Hospital,

Leeds, UK

I R ROBERTSON

1 Haitjema TJ, Overtoom TThC, Westermann CJJ, Lammers JWJ. Embolisation of pulmom The, Westermann CJ, Lammers JWJ. Embolisation of pulmonary arteriovenous malf

2 White RI, Lynch-Nyhan A, Terry P, Buescher PC, Farmlett EJ, Charnas L et al. Pulmonary arteriovenous malformations: techniques and long-term outcome of embolotherapy. Radiology 1988;169:663-9.

3 Remy J, Remy-Jardin M, Wattinne L, Deffontaines C. Pulmonary arteriovenous malformations: evaluation with CT of the chest before and after treatment. Radiology 1992;182:809-16.

4 Remy J, Remy-Jardin M, Giraud F, Wattinne L. Angio architecture of pulmonary arteriovenous malformations: clinical utility of three-dipulmonary arteriovenous malformations: clinical

5 Burke CM, Safai C, Nelson DP, Raffin TA. Pulmonary arteriovenous malformations: a critical update. Am Rev Respir Dis 1986;134:334-9.

6 Remy-Jardin M, Wattinne L, Remy J. Transcatheter occlusion of pulmonary arterial circulation and collateral supply: failures, incidents and complications. Radiology 1991;180:699-705.

7 Jackson JE, Whyte MKB, Allison DJ, Hughes JMB. Coil embolization of pulmonary arteriovenous malformations. Cor Vasa 1990;32:191-6.

8 Puskas JD, Allen MS, Moncure AC, Wain JC, Hilgenburg AD, Wright C, et al. Pulmonary arteriovenous malformations: therapeutic options. Ann Thorac Surg 1993;56:253-8. 